\title{
EDITORIAL
}

\section{Need and efficacy of training courses For editors of Biomedical Journals}

Shireen Jawed

Innovative scientific knowledge is constantly being added to the medical field due to increasing trend of advanced scientific developments in the medical sciences 1 with the result that scientifically accurate and valuable medical research has a great impact on human health and longevity. It also permits rigorous exploration of risk of diseases and is beneficial in discovering new diagnostic tools and treatments, ${ }^{2}$ hence it is essential to promote critical thinking and encourage post-graduate and undergraduate medical students to expand their writing skills. To promote innovative researches in medical sciences and to provide forum for researchers to publish their scientific contributions with a minimum financial burden, there is need to publish peer-reviewed and high standard journals on a broad range of medical sciences. ${ }^{2}$ We do need more good quality peer reviewed medical journals in Pakistan which provide cutting edge updates and developments in the medical arena which will help to synchronize the knowledge of medical community. Accomplishment of the highest level of ethical medical journalism is another important factor. Numerous medical journals are being published from Pakistan ,but unfortunately there is paucity of quality journals. ${ }^{1}$ At present only three medical journals from Pakistan including, Pakistan Journal of Medical Sciences (PJMS), Journal of Pakistan Medical Association (JPMA) and Journal of College of Physicians \& Surgeons Pakistan(JCPSP) fulfill the criteria of standard and international ranking of medical journals and have earned impact factors (IF), which reflects the high number of citations of their publications. IF measures a ratio of citations to a journal in a given year to the citable items in the prior two years. ${ }^{3}$ Authoritative resource for impact factor data is Journal Citation Reports (JCR), issued by Clarivate Analytics incorporated with Web of Science. ${ }^{4}$ Many other Pakistani journals are doing their best efforts for uplifting their journals by improving standard of publications and overcoming shortcomings, but many

\section{Correspondence:}

Dr. Shireen Jawed

Editor

Email: drshireenjawed@gmail.com of them have so far failed to improve quality of journals with the result that some of them have been derecognized by PMDC and HEC. ${ }^{5}$

There are so many causes of failure of these journals. The most important being the inexperienced and untrained editors. Other possible reasons include that most of these editors are faculty members who are already overburdened with their job responsibilities, they are working as part time editor and cannot pay full attention to editing. ${ }^{5}$ Editing a good quality peer reviewed medical journal is a very frustrating and stressful job and increased workload on these part time editors would compromise the quality of the manuscripts. ${ }^{6}$ Other reason of failure is that the medical colleges want to publish the journals but they have failed to provide proper office and minimum required staff to the editor which are the pre-requisite for running successful journals. Regular successful publications and editing is the full time job and require a competent editor supported by an editorial team and staff. $^{7}$ There is a broad range of professional competencies required to be an editor of a scientific journal and it is not possible for an individual to fulfill all these requirements. The editor has to depend on teamwork in which people with different expertize in different areas put together their efforts to produce a good quality peer reviewed journal. ${ }^{8}$

Lack of editorial Independence is yet another important reason for poor quality of journals. ${ }^{5}$ Unavailability of peer reviewer, scientific misconduct including plagiarism, and upholding professional ethics has made the task of the editors more challenging. ${ }^{9}$ Experienced editors have highlighted the deficiencies in various medical journals and also emphasized on the maintenance of quality of journals at different platforms. Publications of various journals in Pakistan are not up to the minimum desired level due to inexperienced editorial team and lack of editorial Independence. It is important that medical journals should have transparent policies. ${ }^{5}$ Poor quality of research gets published in many journals by faculty members without any editorial processing and peer review since they need it for promotion. Some editors also misuse their position which is unethical. ${ }^{5}$ Editor have a moral duty to promote correct information globally that will be useful for health care system. ${ }^{\mathbf{1 0}}$ 
Editors need to be experienced, ethical and professional. They have to face pressures from different quarters. Editors must have decision power, show patience, dedications and to be loyal to their job. ${ }^{5}$

Eastern Mediterranean Association of Medical Editors (EMAME) has been organizing some training courses for the editors in this region. A train the trainer's course was organized by EMAME at Shiraz University of Medical Sciences Shiraz, Islamic Republic of Iran where one delegate form each Eastern Mediterranean Region (EMR) countries was invited. ${ }^{8}$ Pakistan Association of Medical Editors (PAME) is also endeavoring to improve the professional capacity of medical editors of journals published from Pakistan by organizing training courses, conferences, seminars and hand on skills workshops to enhance the professional skill at Karachi, Lahore, Rawalpindi-Islamabad and Peshawar. ${ }^{8}$

Shaukat et al first suggested starting a Certificate Course in Medical Journalism at EMAME conference on Medical Journals held at Bahrain in 2008. ${ }^{11}$ University of Health Sciences Lahore has recently started a Certificate Course in Medical Editing (CME).12 This six month basic course has two contact sessions of four days each and each candidate has been assigned a facilitator/mentor. There will be during the course assessment besides final assessment based on assignment portfolio. ${ }^{12}$ Those who complete this basic course will be eligible for admission to the Advance Course in Medical Editing which will also be of six months duration with two contact sessions of four days each. There will be during the course assessment besides a final assessment based on the portfolio. ${ }^{12}$ All this became possible due to the untiring efforts of Pakistan Association of Medical Editors (PAME). Mr.Shaukat Ali Jawaid Chief Editor of Pakistan Journal of Medical Sciences is the Course Coordinator and many distinguished editors from Pakistan and overseas are included among the facilitators/mentors. If all goes well, the UHS plans to offer degree programs leading to Masters in Medical Journalism in the days to come. It also offers a unique opportunity for the young new editors to learn. ${ }^{4}$ It is hoped that this initiative will speed up the training of editors in all aspects of editorial processing including Editor's triage, peer review process, copy editing, how to withstand pressure particularly from the authors, ensure editorial independence besides helping the authors who are willing to learn. Training of editors how to use Open Journal System for manuscript management is yet another fascinating part of this Certificate Course in Medical Editing. ${ }^{4}$
Accredited medical editing courses with the prime objective of professional capacity building of the editors, newly appointed editors as well as those who wish to take up this as a career were very much needed. With the start of such courses, it is hoped that the standard and quality of scientific manuscripts and biomedical journals published from Pakistan will improve. Flawless editing, peer review and upholding publication ethics will ensure conveying the succinct, impactful medical information to readers.

Talented editorial teams under the leadership of trained editors are required for publishing good quality peer reviewed medical journals. Hence scholarly medical journals should be published and promoted in Pakistan which fosters responsible and balanced debate on controversial issues which will also enhance Pakistan's contribution to world medical literature which is very disappointing at present. Before starting the medical journals logistic and technical issues must be resolved including obtaining a Declaration from government, selection of an editor besides provision of the minimum staff for journal to cope the stress full job and maintain high standards of journals. ${ }^{7}$ It is a collective responsibility of the regulatory bodies including Higher Education Commission (HEC) and Universities to promote the publication of good quality standard journals. Many Medical and Dental Colleges have either started or plan to publish their own journals but they must ensure that all essential steps are taken before starting publication.

Conflict of Interest: This editorial was part of the assignment during the Certificate Course in Medical Editing by UHS Lahore.

\section{REFERENCES}

1. Jain V. Medical research in India and the rise of noncommunicable disease BMJ. 2016;353: i3371. doi: https: //doi.org/10.1136/bmj.i3371.

2. Ahmed B, Husain A, Dossani K. Impact factor of Pakistan Medical Journals. J Pak Med Assoc.. 2013 :63 63(1):131.

3. Jawaid SA, J awaid M. Impact Factor is Off the Ventilator: Survives and is Thriving. Pak J Med Sci. 2018;34(6):13171319.doi:10.12669/pjms.346.1665.

4. Jawaid SA. Certificate in Medical Editing 2019 University University of Health Sciences, Lahore. http://www.uhs.edu .pk/downloads/coursecme.pdf.

5. Jawaid SA. Proceedings of $4^{\text {th }}$ National Conference of Pakistan Association of Medical Editors held at Khyber Medical University, Peshawar. Pak J Med Sci. 2018;34(2): 511-517. doi: https://doi.ord/10.12 669/pjms.342.15180.

6. Jawaid SA, Jawaid M. Are the Editors faced with eproblems performing their duties and responsibilities 
satisfactorily? Pak J Med Sci 2013;29(5):1087-1092.doi: http://dx.doi.org/10.12669/pjms.295.4179.

7. Jawaid SA, Jawaid MA. How to run a successful Journal. Pak J Med Sci. 2017;33(6):1517-1520. doi: https://doi.org/10.12669/pjms.336.14097

8. Jawaid SA, Jawaid M. Professional competencies required for Editors of Biomedical Journals. Pak J Med Sci. 2017; 33(5):1050-1052.doi:https://doi.org/10.12663/pjms.335.13 967.

9. Jawaid SA, Professionalism in Medical Journalism and Role of HEC, PM \& DC. Editorial. Ann King Edward Med Uni.2016; 22(3): 164-165.
10. Kothari R, Bokariya P, Nongrum SM, Singh R. An account on the count of mushrooming journals. Int J Clin Exp physiol.2018;5:54-55.

11. Jawaid SA. Lessons learnt at Eastern Mediterranean Medical Journals conference (EMAMJ4) at Bahrain. Pak J med Sci. 2008; 24(6):769-771.

12. Jawaid SA, Jawaid M. Professional capacity building of Health Science Journal Editors. Pak J Med Sci. 2019; 35 (4):879-881. doi:https://doi.org/10.12669/ pjms.35.4.1299. 